\title{
Liquid biphasic flotation for the purification of C-phycocyanin from Spirulina platensis
}

microalga

Kit Wayne Chew ${ }^{a}$, Shir Reen Chia a ${ }^{a}$, Rambabu Krishnamoorthy ${ }^{b}$, Yang Tao ${ }^{c}$, Dinh-Toi Chu ${ }^{\text {d,e,f }}$, Pau Loke Show ${ }^{\text {a,* }}$

${ }^{\text {a }}$ Department of Chemical and Environmental Engineering, Faculty of Science and Engineering, University of Nottingham Malaysia, 43500 Semenyih, Selangor, Malaysia

${ }^{\mathrm{b}}$ Department of Chemical Engineering, School of Chemical Engineering, Vellore Institute of Technology, Vellore 632014, India

${ }^{\mathrm{c}}$ College of Food Science and Technology, Nanjing Agricultural University, 1 Weigang Road, Nanjing, Jiangsu 210095, China

${ }^{\mathrm{d}}$ Faculty of Biology, Hanoi National University of Education, 136 Xuan Thuy, Cau Giay, Hanoi, Viet Nam

${ }^{\mathrm{e}}$ Institute for Research and Development, Duy Tan University, Danang, Viet Nam

${ }^{\mathrm{f}}$ School of Odonto Stomatology, Hanoi Medical University, Hanoi, Viet Nam

\section{*Corresponding author:}

Department of Chemical and Environmental Engineering, Faculty of Science and Engineering, University of Nottingham Malaysia, 43500 Semenyih, Selangor, Malaysia.

Email: PauLoke.Show@nottingham.edu.my; Tel: +6 (03) 89248605 


\begin{abstract}
Liquid biphasic flotation (LBF), an integrated process of liquid biphasic system (LBS) and adsorptive bubbles flotation, was used for the purification of C-phycocyanin from $S$. platensis microalgae. Various experimental parameters such as type of phase forming polymer and salt, concentration of phase forming components, system $\mathrm{pH}$, volume ratio, air flotation time and crude extract concentration were evaluated to maximise the Cphycocyanin recovery yield and purity. The optimal conditions for the LBF system achieving C-phycocyanin purification fold of 3.49 compared to 2.43 from the initial LBF conditions was in polyethylene glycol (PEG) 4000 and potassium phosphate combination, with $250 \mathrm{~g} / \mathrm{L}$ of polymer and salt concentration each, volume ratio of 1:0.85, system $\mathrm{pH}$ of 7.0, air flotation duration of $7 \mathrm{~min}$ and phycocyanin crude extract concentration of $0.625 \%$ w/w. The LBF has effectively enhanced the purification of C-phycocyanin in a cost effective and simple processing.
\end{abstract}

Keywords: C-phycocyanin, liquid biphasic flotation; pigment; purification; Spirulina platensis 


\subsection{Introduction}

The importance of high-value natural products that can be obtained from renewable source and their nutritional quality have been growing in recent times. Third generation feedstock like microalgae have shown great potential in the generation of valuable products depending on the strain (Chew et al., 2018a; Chew et al., 2018b). The cyanobacterium $S$. platensis has been on the spotlight for its great potential in the production of food and nutritional compounds, namely, proteins, carbohydrates, vitamins, fatty acids and food colorants (Kulshreshtha et al., 2008). One of the major pigments that can be extracted from S. platensis is C-phycocyanin (C-PC). C-PC is a natural blue pigment that is part of the phycobiliprotein group in the proteins present in Spirulina. C-PC is widely used in food processing and cosmetic industry and possess anti-oxidant, anti-inflammatory and anticancer activity. It can help to modulate lipid and carbohydrate metabolisms and control the occurrence of chronic diseases like obesity, cardiovascular disease and diabetes (Chew et al., 2017; Khan et al., 2005). These benefits have led to researchers putting focus on the development of an efficient process for the commercial extraction and purification of phycocyanin.

The main difficulties in phycocyanin purification involves the great number of processing steps whereby precipitation, centrifugation and dialysis are used in the initial purification, followed by ion-exchange chromatography and gel filtration chromatography in the final purification (Chew et al., 2019; Patil \& Raghavarao, 2007). These long steps needed for phycocyanin purification will result in higher product yield loss, apart from posing difficulties in the scale-up process. The major portion of production costs arises from the purification steps, hence, a more efficient and economical large-scale 
bioseparation method is required to help elevate the costly conventional processing for phycocyanin purification.

Liquid biphasic system (LBS), also known as aqueous two-phase system (ATPS), is an economical and effective downstream processing that has been widely used in the recovery of bioproducts. This technique is favoured for its simplicity, high extraction efficiency, biocompatibility, ease of operation, rapid processing time and feasibility for scale-up (Lee et al., 2017; Phong et al., 2018). LBS consists of two hydrophilic but immiscible solutions, made using either polymer/salt, alcohol/salt or other combinations. The partitioning behavior of biomolecules such as proteins in LBS can be affected by the type of raw materials used, concentration of the polymer/salt, volume ratio, temperature, pH of the system, biomass concentration and many more (Asenjo \& Andrews, 2012; Chia et al., 2018). LBS has been successfully used for the downstream processing of C-PC from Spirulina, for example: ATP extraction with PEG and salt (Patil \& Raghavarao, 2007), ATPS with ionic liquid and salt (Chang et al., 2018; Zhang et al., 2015), integrated ATPS with cell debris (Antelo et al., 2010) and vortex fluidic device-intensified ATP extraction (Luo et al., 2016). These processes have demonstrated the potential purification of C-PC using multiphase systems which are able to yield high recoveries with low cost operation and are suitable for food processes.

Liquid biphasic flotation (LBF) is an emerging bioseparation process for the extraction and purification of biomolecules (Sankaran et al., 2018). The LBF system is an integration of the conventional LBS and adsorptive bubbles flotation system, where the biphasic system is supported with air bubbling to transport the biomolecules from one phase to another. The surface-active compound of biomolecules present will adsorb onto 
the surface of the ascending gas bubbles and be brought from the bottom aqueous phase to the top organic phase. LBF has been applied for the purification of various biomolecules which include lipase from Burkholderia cepacia (Sankaran et al., 2018; Show et al., 2013), proteins from microalgae (Chia et al., 2019), betacyanin from Hylocereus polyrhizus (Leong et al., 2018) and many more. The LBF which contains the benefits of both LBS and bubbles flotation, has shown to achieve high separation efficiency, ease of operation and environmental friendliness. This indicates that LBF has high prospects for the purification of biomolecules from microalgae.

The aim of this study was to investigate the potential of integrating LBS and adsorptive bubbles flotation system in a combined LBF the purification of C-PC from $S$. platensis. The LBF study was conducted by optimizing the operating conditions and evaluating the yield and separation efficiency of C-PC. The parameters that were investigated include types of PEG and salts, concentration of PEG and salt, volume ratio, $\mathrm{pH}$ of the system, air flotation time and crude extract concentration. The molecular weights of the C-PC purified were established through SDS-PAGE tests.

\subsection{Materials and methods}

\subsection{Materials}

Dipotassium hydrogen phosphate $\left[\mathrm{K}_{2} \mathrm{HPO}_{4}\right]$, potassium dihydrogen phosphate $\left[\mathrm{KH}_{2} \mathrm{PO}_{4}\right]$, ammonium sulphate $\left[\left(\mathrm{NH}_{4}\right)_{2} \mathrm{SO}_{4}\right]$, magnesium sulphate $\left[\mathrm{MgSO}_{4}\right]$, sodium dihydrogen phosphate $\left[\mathrm{NaH}_{2} \mathrm{PO}_{4}\right]$, Polyethylene glycol (PEG) 4000, PEG 8000, phosphate buffer and sodium chloride $[\mathrm{NaCl}]$ were purchased from R\&M chemicals (Malaysia). PEG 2000 was 
purchased from Alfa Aesar (UK). Dried S. platensis powder was purchased from Charming \& Beauty Co. Ltd. (Taipei, Taiwan). All chemicals used were of analytical grade.

\subsection{Preparation of crude phycocyanin extract}

S. platensis dried powder were dissolved in phosphate buffer and disrupted using an ultrasonicator (Elma, Germany) at $35 \mathrm{kHz}$ (40\% amplitude) for $5 \mathrm{~min}$. The suspension was then centrifuged at $6500 \mathrm{rpm}$ for $10 \mathrm{~min}$. The resulting supernatant was separated from the cell debris and stored at $4^{\circ} \mathrm{C}$ for further purification studies.

\subsection{Liquid biphasic flotation technique}

The LBF apparatus used was adapted from the work by Leong et al. 2018 (Leong et al., 2018). The LBF system consists of a glass filter funnel of $20 \mathrm{~cm}$ length and $2 \mathrm{~cm}$ diameter with a sintered glass disk (Grade G4 porosity) installed at the bottom of the funnel. Air was supplied using a pump and air bubbles of average size 5-15 $\mu \mathrm{m}$ were generated when the air passed through the sintered glass disk. Figure 1 illustrates the schematic diagram and concept of phycocyanin purification from Spirulina crude extract using PEG/salt-based LBF. The LBF of predetermined properties was generated by initially adding $300 \mathrm{~g} / \mathrm{L}$ PEG solution (20 ml) into $250 \mathrm{~g} / \mathrm{L}$ of potassium salt solution (20ml) premixed with $0.5 \% \mathrm{w} / \mathrm{w}$ crude phycocyanin extract. The aqueous mixture was aerated with air flow of 0.5-0.75 vvm (volume of gas per volume of medium per min) for a duration of 5 min. The mixture was then transferred to a centrifuge tube and allowed to settle and separate into two phases for $30 \mathrm{~min}$. One-variable-at-a-time (OVAT) approach was used to investigate the effects of different parameters on the purification of phycocyanin from the 
microalgae. The operating parameters of the LBF system such as types of PEG, type of salt, concentration of PEG, concentration of salt, volume ratio of salt to polymer, $\mathrm{pH}$ of the system, air flow duration and concentration of crude extract were optimized for the phycocyanin purification. The initial settings and variables of the LBF system are listed in Table 1.

\subsection{Analytical procedures}

\subsubsection{Determination of C-phycocyanin concentration}

C-PC concentration was determined according to Bennett and Bogorad (1973)

(Bennett \& Bogorad, 1973) using Equation (1), where CPC is the C-phycocyanin concentration $(\mathrm{mg} / \mathrm{ml}), \mathrm{OD}_{615}$ is the optical density of the sample at $615 \mathrm{~nm}$ and $\mathrm{OD}_{652}$ is the optical density of the sample at $652 \mathrm{~nm}$ :

$$
C P C=\frac{O D_{615}-0.474 \times O D_{652}}{5.34} \quad \text { Equation (1) }
$$

The purity of C-PC (PT) was calculated spectrophotometrically according to Abalde et al. 1998 (Abalde et al., 1998) using Equation (2), where $\mathrm{OD}_{620}$ is the optical density of the sample at $620 \mathrm{~nm}$, which represents the maximum absorption of C-PC, and $\mathrm{OD}_{280}$ is the optical density of the sample at $280 \mathrm{~nm}$, which represents the total proteins in the solution. This purity is an indication of the pureness of C-PC extract with respect to other contaminating proteins. The purification factor $(\mathrm{PF})$ is calculated by using the purity of the sample divided by the purity of the crude extract (Equation (3)): 


$$
\begin{array}{ll}
P T=\frac{O D_{620}}{O D_{280}} & \text { Equation (2) } \\
P F=\frac{P T_{\text {top }}}{P T_{\text {crude }}} & \text { Equation (3) }
\end{array}
$$

The partition coefficient (K) was calculated using Equation (4), where $\mathrm{CPC}_{\mathrm{t}}$ and $\mathrm{CPC}_{\mathrm{b}}$ are the concentration of C-phycocyanin $(\mathrm{mg} / \mathrm{ml})$ in the top and bottom phases, respectively.

$$
K=\frac{C P C_{t}}{C P C_{b}} \quad \text { Equation (4) }
$$

The volume ratio $\left(\mathrm{V}_{\mathrm{r}}\right)$ is the ratio between the volumes of the top and bottom phases and can be calculated using Equation (5):

$$
V_{r}=\frac{V_{t}}{V_{b}} \quad \text { Equation (5) }
$$

The recovery yield $(\mathrm{RC}, \%)$ of the C-PC from the sample was calculated using Equation (6):

$$
R C=\frac{K \times V_{r}}{1+K \times V_{r}} \quad \text { Equation (6) }
$$

\subsubsection{Gel electrophoresis}

Ultrafiltration units (Amicon Ultra, Millipore) were used for the separation of PEG from the C-PC solution prior to gel electrophoresis. Sodium dodecyl sulphate-polyacrylamide gel electrophoresis (SDS-PAGE) was conducted as described by Deutscher's method (Deutscher, 1990), using a 30\% polyacrylamide slab gel, running in a vertical gel electrophoresis unit. Electrophoresis was run at $50 \mathrm{~V}, 12.5 \mathrm{~mA}$, for $3-4 \mathrm{~h}$. The gel was 
stained with a solution containing $0.05 \%$ w/w Coomassie Brilliant Blue R250 and destained using deionized water.

\subsection{Results and Discussion}

\subsection{Effect of PEG molecular weight}

The LBF study was performed using polyethylene glycol of different molecular weights, namely PEG 2000, PEG 4000 and PEG 8000. The phase compositions were set at $300 \mathrm{~g} / \mathrm{L}$ of polymer and $250 \mathrm{~g} / \mathrm{L}$ of salt for a system with polymer/salt volume ratio of 1:1. The influence of PEG molecular weight on the recovery yield and purification fold of C-PC are shown in Table 2. PEG 4000 obtained the highest yield (RC) at 81.2\% while PEG 2000 obtained the best purification fold (PF) of 2.60. The RC for PEG 2000 was the lowest while for PF the lowest was found at PEG 8000. The increase in PEG molecular weight will lead to less hydroxyl groups present, hence, increasing the top phase hydrophobicity. By adding similar concentrations of polymer, the higher molecular weights of PEG will induce higher chain lengths of the polymer that results in less free volume in the top phase for proteins. This indicates that lower molecular weight of PEG will have more free volume and hence more proteins will be present at the top phase (Patil \& Raghavarao, 2007), where a lower concentration of C-PC was found at the top phase of PEG 2000. On the other hand, increasing the PEG molecular weight from 4000 to 8000 facilitated the partitioning of proteins and C-PC to the bottom phase as there are less space for proteins at the top phase, resulting in a lower yield and purity. Higher molecular weight of PEG also has lower solubility and creates a thicker solution that may reduce the effectiveness of the air bubbles from transporting the C-PC to the top phase. The purity of both PEG 2000 and PEG 4000 
does not vary significantly but the yield of PEG 2000 is much lower compared to PEG 4000. In view of this, PEG 4000 was selected for further experiments.

\subsection{Effect of types of salt}

The selection of suitable salts for the purification of C-PC can affect the partitioning of proteins to the top phase. Different salts like ammonium sulphate, magnesium sulphate, dipotassium hydrogen phosphate and sodium dihydrogen phosphate were studied in the polymer/salt LBF. PEG 4000 was the polymer used as the upper phase for all the salt combinations (Table 2). The highest RC was found for ammonium sulphate while the highest purity was obtained by dipotassium hydrogen phosphate. The lowest yield and purity were observed when magnesium sulphate was used as the salt in LBF. It is essential to select the salt which can provide an initial $\mathrm{pH}$ that is higher than the $\mathrm{pI}$ of C-PC to allow for better partitioning. Ammonium sulphate has been commonly used for the precipitation of proteins in protein and enzymes purification process. The high $\mathrm{RC}$ of ammonium sulphate could be attributed to the sulphate ions which interact well with water, hence, forming good hydration capacity and affinity for water that increases protein yield. However, much of the undesired proteins are also partitioned to the top phase, leading to lower purity of C-PC. Both ammonium sulphate and magnesium sulphate produced a system of $\mathrm{pH}$ 4.5-5.5, which may have caused the C-PC to be unstable. Phosphate salts, on the other hand, are able to provide a comfortable phase environment ( $\mathrm{pH}$ 6.0-8.0) for the proteins in LBF system, resulting in better purity of C-PC and good recovery yield. Patil and Raghavarao (2007) reported that among the salts tested (phosphate, sulphate, citrate), phosphate salts showed the maximum purity as well (Patil \& Raghavarao, 2007). 
Comparing both phosphate salts (Dipotassium hydrogen phosphate and sodium dihydrogen phosphate), dipotassium hydrogen phosphate showed higher RC and PF, hence, the PEG/potassium phosphate system was selected for subsequent experiments.

\subsection{Effect of polymer and salt concentration}

Changes in the polymer and salt concentration will directly influence the phase composition of the biphasic system. These changes will affect the interfacial tension, density and viscosity of the system due to the variation occurring in solute partitioning. The partitioning of C-PC was studied by adjusting the polymer concentration in the range of $200-400 \mathrm{~g} / \mathrm{L}$ and the salt concentration in the range of 200-350 g/L. Figure 2(a) shows the effects of polymer concentration on the C-PC recovery yield and purification fold. Increasing the polymer concentration above the initial setting of $300 \mathrm{~g} / \mathrm{L}$ showed a lower $\mathrm{RC}$ and PF. Lowering the polymer concentration down to $200 \mathrm{~g} / \mathrm{L}$ showed an increase in both the RC and PF for $250 \mathrm{~g} / \mathrm{L}$ but decreased at $200 \mathrm{~g} / \mathrm{L} .250 \mathrm{~g} / \mathrm{L}$ of polymer concentration produced the best RC (86.3\%) and PF (2.63). Increasing the polymer concentration will increase the volume of the top phase, which encourages the partitioning of contaminating proteins to the top, this would lead to a lower purity of C-PC compounds in the top phase (Chethana et al., 2015). The higher concentration of polymer also tends to cause foaming during the bubbling process in the LBF system, where the top polymer phase will be reduced as the solution foams at the top. Foaming is less apparent when the lower concentration of polymer is used. The decrease in polymer concentration will result in less free volume available for the protein and hence C-PC will be more concentrated at the top. However, too little free volume would result in the insufficient space for C-PC to be 
partitioned to the top. Less polymer concentration also results in lower top phase volume whereby the air bubbles flow through a longer distance of the bottom phase, adsorbing more contaminating proteins to the top phase before dispersing at the surface. Based on the findings, polymer concentration of $250 \mathrm{~g} / \mathrm{L}$ was selected for the next study.

The concentration of salt was altered while keeping the polymer concentration constant. The effects of salt concentration on the C-PC recovery yield and purification fold are shown in Figure 2(b). The increase in salt concentration up to $350 \mathrm{~g} / \mathrm{L}$ led to much lower RC and lower PF, on top of that, decreasing the salt concentration to $200 \mathrm{~g} / \mathrm{L}$ also led to a large decrease in $\mathrm{RC}$ and $\mathrm{PF}$. Increase in the salt concentration will decrease the top phase volume, creating less free space for proteins and C-PC, hence, reducing the yield and purity of C-PC. The high concentrations of salt also caused slight precipitation of C-PC. The higher volume of bottom phase would contain more C-PC and this has significantly affected the yield. At lower salt concentrations $(200 \mathrm{~g} / \mathrm{L})$, the top phase volume is higher, this indirectly also increase the free volume which would be taken by C-PC and the contaminating proteins. Coupled with the gas flotation effect, more contaminating proteins would be brought to the top phase and cause a lower purity of C-PC. Chethana et al. (2015) reported that the increase in salt concentration led to the significant increase in the change in free volume, resulting in increased partitioning of $\mathrm{C}-\mathrm{PC}$ and contaminating proteins to the top phase (Chethana et al., 2015). Hence, $250 \mathrm{~g} / \mathrm{L}$ of salt concentration was selected to remain for the subsequent experiments. 


\subsection{Effect of volume ratio}

The phase volume ratio can alter the volume in each phase in a liquid biphasic system, leading to changes in the concentration, yield and purity of biomolecules recovered. The volume ratio of bottom to top phase was adjusted from 1:0.7 to 1:1.5 to observe the concentration of the targeted protein in each phase (Figure 3(a)). As the volume ratio increases, the yield of C-PC increased, while the purity decreased. The highest PF (2.91) was found at the volume ratio of 1:0.85, which showed an $11 \%$ increase from the initial setting at $1: 1$, although the RC dropped slightly by $3.4 \%$. Lower RC and PF were observed in the lowest volume ratio used, and despite having the best RC for volume ratio of 1:1.5, the PF was much lower compared to the volume ratio of 1:0.85. The increase in volume ratio will result in a higher volume of top phase, which allows for both C-PC and the contaminating proteins to concentrate there. This would increase the yield of C-PC but reduce its purity as there will be a lot of contaminating proteins in the top phase. On the other hand, decreasing the volume ratio will lead to lower volume for the top phase and a higher total salt concentration in the system, meaning that there will less free volume for both the C-PC and proteins. The influence of salt on the partitioning is caused by the nonuniform distribution of the salt in both phases through the difference in electric potential. This facilitates the movement of proteins to the other phase through electrostatic attraction or repulsion (Nagaraja \& Iyyaswami, 2015). A lower volume in the top phase would also allow for less volume for the ascending bubbles to release the $\mathrm{C}$-PC in the top phase, where the bubbles will likely bring more contaminating proteins from the bottom to the top, leading to a lower purity. The PF of the volume ratio 1:0.85 was the highest, despite its RC being slightly lower. This volume ratio was selected for the further experiments. 


\subsection{Effect of $\mathrm{pH}$}

The extraction $\mathrm{pH}$ is one of the vital parameters that produces substantial effects on the efficiency of C-PC separation. The changes in the $\mathrm{pH}$ value of the system can affect the net charge of C-PC, the charge distribution on the C-PC surface, zeta potential and conformational structure change (Chang et al., 2018). The $\mathrm{pH}$ of the system was adjusted by using various combination of potassium salts to make a final $\mathrm{pH}$ in the range of 6-9. The $\mathrm{pH}$ values range were selected based on the isoelectric point of C-PC, which is 5.8, as there needs to be a balance between the positive and negative charges of the ionic groups of a protein (Antelo et al., 2010). Figure 3(b) shows the influence of $\mathrm{pH}$ of the system on the $\mathrm{RC}$ and $\mathrm{PF}$ of C-PC partitioning. The highest C-PC recovery and purity was observed at $\mathrm{pH}$ 7, with $\mathrm{pH} 8$ and 9 showing comparable purity but slightly lower yields. pH 6 showed the lower yield and purity of the C-PC. The partitioning of C-PC to the top of the system depicts that C-PC is more soluble in the PEG rich phase, where it will be more concentrated depending on the charge-charge interaction. The $\mathrm{pH}$ value higher than the $\mathrm{pI}$ of C-PC with negative charge will make the C-PC favour the top polymer phase, while the other proteins with positive charges will partition to the bottom phase. Patil and Raghavarao (2007) specified that at $\mathrm{pH} 6$, the partitioning of $\mathrm{C}-\mathrm{PC}$ was due to the surface properties rather than net charge as the difference of isoelectric point of C-PC and the $\mathrm{pH}$ was very small. While for $\mathrm{pH}$ of 7 and 8 , the C-PC would be negatively charged and thereby attracted by the PEGrich phase (Patil \& Raghavarao, 2007). This means that C-PC would get partitioned to the top phase and the contaminating proteins would go to the opposite phase (bottom phase). Further increase in $\mathrm{pH}$ to 9 will lead to $\mathrm{C}-\mathrm{PC}$ denaturation and conformational changes as 
even the Spirulina cells would be unable to survive at high $\mathrm{pH}$. This is also supported by the fact that C-PC is mostly found to be stable at pH of 6 to 8 (Antelo et al., 2008). Higher $\mathrm{pH}$ will also increase the free volume in the top phase, allowing more contaminating proteins to go to the top. The $\mathrm{pH}$ of 7 proved to be the best in terms of $\mathrm{RC}$ and $\mathrm{PF}$ of $\mathrm{C}-\mathrm{PC}$ and hence, this $\mathrm{pH}$ was selected for the subsequent experiment.

\subsection{Effect of air flotation time}

The air flotation time contributes significantly in the LBF system as this parameter affects the area of air-water interface per unit volume of aqueous solution with time (Sankaran et al., 2018). Besides that, the size of air bubbles are also worth considering as it relates to the available interfacial area for gas-liquid mass transfer. Extremely small bubbles will coalesce into larger bubbles to overcome the interfacial tension (Bi et al., 2010). In this work, the sintered glass disk of G4 porosity size was used as the performance of this porosity size range $(5-15 \mu \mathrm{m})$ was found to be suitable and effective for the biphasic flotation study (Show et al., 2013). The aeration rate was set to be around $0.5-0.75 \mathrm{vvm}$ to avoid the foaming of the polymer phase due to high aeration rate. Different durations of flotation time from 1.5 min to 9 min were evaluated for the LBF system on C-PC partitioning. Figure 4 shows the influence of air flotation time of the system on the C-PC recovery yield and PF. The yield of C-PC increases as the flotation time increased from 1.5 min to $5 \mathrm{~min}$, then the yield drops slightly after $5 \mathrm{~min}$ of flotation time. The purity of C-PC also observes the same trend, increasing up to $7 \mathrm{~min}$ and dropping significantly at 9 min. The highest RC (88.0\%) was found at 5 min with PF of 3.09, while the highest PF (3.16) was found for $7 \mathrm{~min}$, with a $\mathrm{RC}$ of $86.9 \%$. Increasing the flotation time increases the 
transportation of the C-PC from the bottom phase to the top phase, however, too long a duration will also encourage the partitioning of contaminant proteins to the top. Lower flotation time are insufficient for effective C-PC partitioning to the top phase, while higher flotation time showed comparable yields but a reduction in purity of C-PC. Other research works on flotation also showed that extending the flotation time will result in a slight decrease on yield and separation efficiency, indicating that there was no need to extend the flotation time for too long periods (Leong et al., 2018; Phong et al., 2018). Air flotation time of 7 min showed the highest purity and comparable C-PC yield with the initial setting of $5 \mathrm{~min}$, hence $7 \mathrm{~min}$ was selected as the suitable flotation time for the next experiment on biomass concentration, where extension of the flotation time beyond 7 min was deemed unnecessary.

\subsection{Effect of crude extract concentrations}

The partitioning behavior of the proteins will be affected by the amount of feedstock in the system. Crude extract concentrations which are too high will result in a more viscous solution which may cause difficulties in the separation process, while lower crude extract concentration makes the process less effective as the total product recovery would be lower (Chia et al., 2019). The crude extract concentration was investigated in the range of 0.25 to $0.75 \%$ w/w. From Figure 5, the concentration of $0.625 \% \mathrm{w} / \mathrm{w}$ gives the highest RC (90.4\%) and PF (3.49). The increase and decrease in crude extract concentration both showed increasing C-PC recovery but lower purity. The lowest yield and purity was found for concentration of $0.375 \% \mathrm{w} / \mathrm{w}$. At lower crude extract concentration, there will be more space available for both C-PC and the undesired proteins, hence the yield is higher 
but a drop in purity was observed. Lower crude extract concentration is also not favourable as the production output of $\mathrm{C}-\mathrm{PC}$ will be lower and this makes the purification process less cost-effective. With increasing crude extract concentration, the yield of C-PC increases, and the purity of C-PC increases as well up to $0.625 \% \mathrm{w} / \mathrm{w}$, then it decreases at $0.75 \% \mathrm{w} / \mathrm{w}$. The higher concentration of C-PC with higher crude extract concentration requires more work from the air bubbles to transport the C-PC to the top phase. As both the C-PC and contaminating proteins are present in large volumes, higher proportions of the proteins will be transported to the top phase, leading to a lower purity. In this study, the crude extract concentration of $0.625 \% \mathrm{w} / \mathrm{w}$ showed the best RC and PF, compared to the initial setting of $0.5 \% \mathrm{w} / \mathrm{w}$. This is likely due to the available free volume in the top phase that can accommodate additional C-PC content, resulting in a slightly higher C-PC yield and purity in the top phase. The crude extract concentration of $0.625 \% \mathrm{w} / \mathrm{w}$ was selected as the most suitable condition for the LBF study.

\subsection{SDS-PAGE}

SDS-PAGE analysis of C-PC purity from the crude extract of S. platensis was performed to determine the molecular weights of the C-PC subunits. The purified top phase of the LBF system were subjected to gel electrophoresis as shown in Figure 6. Lane A indicates the molecular marker, lane B indicates the crude extract of C-PC and lane C shows the C-PC after LBF process. From the SDS-PAGE, the C-PC shows two bands in the range of 18 and $20 \mathrm{kDa}$. The bands present are in accordance with other works done by purifying C-PC from S. platensis, which shows that C-PC are apparent in the band range of 18 and $20 \mathrm{kDa}$ (Chethana et al., 2015; Patil \& Raghavarao, 2007). After LBF, the majority 
of the contaminant proteins present in the crude extract have been partitioned to the bottom phase, resulting in less bands in the lane C compared to Lane B. This shows the potential of LBF for the effective purification of C-PC from microalgae.

\subsection{Conclusion}

The purification of C-phycocyanin from $S$. platensis was performed using LBF, which is a combination of LBS and adsorptive bubbles flotation with the incorporation of bubbling effect into the system. The optimized conditions for the LBF was found to be: PEG 4000 and potassium phosphate combination, polymer and salt concentration of 250 $\mathrm{g} / \mathrm{L}$ each, bottom to top volume ratio of 1:0.85, system $\mathrm{pH}$ of 7.0 , air flotation period of 7 min and crude extract concentration of $0.625 \% \mathrm{w} / \mathrm{w}$. The maximum C-PC recovery and purification fold of the optimized LBF system was found to be $90.4 \%$ and 3.49 , respectively.

\section{Acknowledgements}

The authors are grateful to Dr. Ricardo A. Parra-Cruz for his assistance with the SDSPAGE analysis.

\section{Funding}

This work was supported by the Fundamental Research Grant Scheme, Malaysia [FRGS/1/2015/SG05/UNIM/03/1]; the Ministry of Science and Technology, Malaysia [MOSTI02-02-12-SF0256]; the Prototype Research Grant Scheme, Malaysia 
[PRGS/2/2015/SG05/UNIM/03/1]; the International Cooperation Seeds Funding of Nanjing Agricultural University [2018-AH-04].

\section{Declaration of interest:}

None

\section{References}

1. Abalde, J., Betancourt, L., Torres, E., Cid, A., Barwell, C., 1998. Purification and characterization of phycocyanin from the marine cyanobacterium Synechococcus sp. IO9201. Plant Sci. 136(1), 109-120.

2. Antelo, F.S., Anschau, A., Costa, J.A., Kalil, S.J., 2010. Extraction and purification of C-phycocyanin from Spirulina platensis in conventional and integrated aqueous twophase systems. J. Braz. Chem. Soc. 21(5), 921-926.

3. Antelo, F.S., Costa, J.A., Kalil, S.J., 2008. Thermal degradation kinetics of the phycocyanin from Spirulina platensis. Biochem. Eng. J. 41(1), 43-47.

4. Asenjo, J.A., Andrews, B.A., 2012. Aqueous two-phase systems for protein separation: phase separation and applications. J. Chromatogr. A 1238, 1-10.

5. Bennett, A., Bogorad, L., 1973. Complementary chromatic adaptation in a filamentous blue-green alga. The J. Cell Biol. 58(2), 419-435.

6. Bi, P.-y., Dong, H.-r., Dong, J., 2010. The recent progress of solvent sublation. J. Chromatogr. A 1217(16), 2716-2725. 
7. Chang, Y.-K., Show, P.-L., Lan, J.C.-W., Tsai, J.-C., Huang, C.-R., 2018. Isolation of C-phycocyanin from Spirulina platensis microalga using Ionic liquid based aqueous two-phase system. Bioresour. Technol. 270, 320-327.

8. Chethana, S., Nayak, C.A., Madhusudhan, M., Raghavarao, K., 2015. Single step aqueous two-phase extraction for downstream processing of C-phycocyanin from Spirulina platensis. J. Food Sci. Technol. 52(4), 2415-2421.

9. Chew, K.W., Chia, S.R., Lee, S.Y., Zhu, L., Show, P.L., 2019. Enhanced microalgal protein extraction and purification using sustainable microwave-assisted multiphase partitioning technique. Chem. Eng. J. 367, 1-8.

10. Chew, K.W., Chia, S.R., Show, P.L., Ling, T.C., Arya, S.S., Chang, J.-S., 2018a. Food waste compost as an organic nutrient source for the cultivation of Chlorella vulgaris. Bioresour. Technol. 267, 356-362.

11. Chew, K.W., Chia, S.R., Show, P.L., Yap, Y.J., Ling, T.C., Chang, J.-S., $2018 b$. Effects of water culture medium, cultivation systems and growth modes for microalgae cultivation: a review. J. Taiwan Inst. Chem. Eng. 91, 332-344.

12. Chew, K.W., Yap, J.Y., Show, P.L., Suan, N.H., Juan, J.C., Ling, T.C., Lee, D.-J., Chang, J.-S., 2017. Microalgae biorefinery: high value products perspectives. Bioresour. Technol. 229, 53-62.

13. Chia, S.R., Chew, K.W., Show, P.L., Manickam, S., Ling, T.C., Tao, Y., 2019. Isolation of protein from Chlorella sorokiniana CY1 using liquid biphasic flotation assisted with sonication through sugaring-out effect. J. Oceanol. Limnol., 1-11. 
14. Chia, S.R., Show, P.L., Phang, S.-M., Ling, T.C., Ong, H.C., 2018. Sustainable approach in phlorotannin recovery from macroalgae. J. Biosci. Bioeng. 126(2), 220225.

15. Deutscher, M.P. 1990. Guide to protein purification. Gulf Professional Publishing.

16. Khan, Z., Bhadouria, P., Bisen, P., 2005. Nutritional and therapeutic potential of Spirulina. Curr. Pharm. Biotechnol. 6(5), 373-379.

17. Kulshreshtha, A., Jarouliya, U., Bhadauriya, P., Prasad, G., Bisen, P., 2008. Spirulina in health care management. Curr. Pharm. Biotechnol. 9(5), 400-405.

18. Lee, S.Y., Khoiroh, I., Ling, T.C., Show, P.L., 2017. Enhanced recovery of lipase derived from Burkholderia cepacia from fermentation broth using recyclable ionic liquid/polymer-based aqueous two-phase systems. Sep. Purif. Technol. 179, 152-160.

19. Leong, H.Y., Ooi, C.W., Law, C.L., Julkifle, A.L., Ling, T.C., Show, P.L., 2018. Application of liquid biphasic flotation for betacyanins extraction from peel and flesh of Hylocereus polyrhizus and antioxidant activity evaluation. Sep. Purif. Technol. 201, 156-166.

20. Luo, X., Smith, P., Raston, C., Zhang, W., 2016. Vortex fluidic device-intensified aqueous two phase extraction of C-phycocyanin from Spirulina maxima. ACS Sust. Chem. Eng. 4(7), 3905-3911.

21. Nagaraja, V.H., Iyyaswami, R., 2015. Aqueous two phase partitioning of fish proteins: partitioning studies and ATPS evaluation. J. Food Sci. Technol. 52(6), 3539-3548.

22. Patil, G., Raghavarao, K., 2007. Aqueous two phase extraction for purification of Cphycocyanin. Biochem. Eng. J. 34(2), 156-164. 
23. Phong, W.N., Show, P.L., Chow, Y.H., Ling, T.C., 2018. Recovery of biotechnological products using aqueous two phase systems. J. Biosci. Bioeng. 126(3), 273-281.

24. Sankaran, R., Show, P.L., Lee, S.Y., Yap, Y.J., Ling, T.C., 2018. Integration process of fermentation and liquid biphasic flotation for lipase separation from Burkholderia cepacia. Bioresour. Technol. 250, 306-316.

25. Show, P.L., Ooi, C.W., Anuar, M.S., Ariff, A., Yusof, Y.A., Chen, S.K., Annuar, M.S.M., Ling, T.C., 2013. Recovery of lipase derived from Burkholderia cenocepacia ST8 using sustainable aqueous two-phase flotation composed of recycling hydrophilic organic solvent and inorganic salt. Sep. Purif. Technol. 110, 112-118.

26. Zhang, X., Zhang, F., Luo, G., Yang, S., Wang, D., 2015. Extraction and separation of phycocyanin from Spirulina using aqueous two-phase systems of ionic liquid and salt. J. Food. Nut. Res. 3(1), 15-19. 
Table 1: Operating parameters of LBF system for C-phycocyanin purification from $S$. platensis.

\begin{tabular}{lllll}
\hline Step & Operating parameter & Initial & Variables & Unit \\
No. & & condition & & \\
\hline 1 & Type of PEG & - & PEG 2000, PEG 4000, PEG & - \\
& & & 8000 & \\
2 & Type of salts & $\mathrm{K}_{2} \mathrm{HPO}_{4}$ & $\left(\mathrm{NH}_{4}\right)_{2} \mathrm{SO}_{4}, \mathrm{MgSO}_{4}, \mathrm{~K}_{2} \mathrm{HPO}_{4}$, & - \\
& & & $\mathrm{NaH}_{2} \mathrm{PO}_{4}$ & \\
3 & Concentration of PEG & 300 & $200,250,300,350,400$ & $\mathrm{~g} / \mathrm{L}$ \\
4 & Concentration of salt & 250 & $200,250,300,350$ & $\mathrm{~g} / \mathrm{L}$ \\
5 & Volume ratio & $1: 1$ & $1: 0.7,1: 0.85 ; 1: 1,1: 1.25,1: 1.5$ & - \\
6 & pH & 9 & $6,7,8,9$ & - \\
7 & Air flotation time & 5 & $1.5,3,5,7,9$ & $\mathrm{~min}$ \\
8 & Crude extract & 0.5 & $0.25,0.375,0.5,0.625,0.75$ & $\% \mathrm{w} / \mathrm{w}$ \\
& concentration & & & \\
\end{tabular}


Table 2: Effect of polymer molecular weight and salts type on the C-PC recovery yield and purification fold from $S$. platensis.

\begin{tabular}{llccc}
\hline Polymer type & Salt type & Volume ratio & C-PC recovery & Purification \\
& & & yield (\%) & fold \\
\hline Types of polymer & & & \\
PEG 2000 & $\mathrm{K}_{2} \mathrm{HPO}_{4}-$ phosphate & 1.02 & $66.5 \pm 0.83$ & 2.60 \\
PEG 4000 & $\mathrm{K}_{2} \mathrm{HPO}_{4}-$ phosphate & 0.95 & $81.2 \pm 0.28$ & 2.43 \\
PEG 8000 & $\mathrm{K}_{2} \mathrm{HPO}_{4}-$ phosphate & 1.08 & $75.3 \pm 0.13$ & 2.19 \\
Types of salt & & & & 1.63 \\
PEG 4000 & $\left(\mathrm{NH}_{4}\right)_{2} \mathrm{SO}_{4}-$ sulphate & 1.00 & $93.5 \pm 0.52$ & 1.22 \\
PEG 4000 & $\mathrm{MgSO}_{4}-$ sulphate & 1.76 & $66.4 \pm 1.01$ & 1.76 \\
PEG 4000 & $\mathrm{NaH}_{2} \mathrm{PO}_{4}-$ phosphate & 1.97 & $74.7 \pm 0.14$ & \\
\hline
\end{tabular}




\section{Figures:}

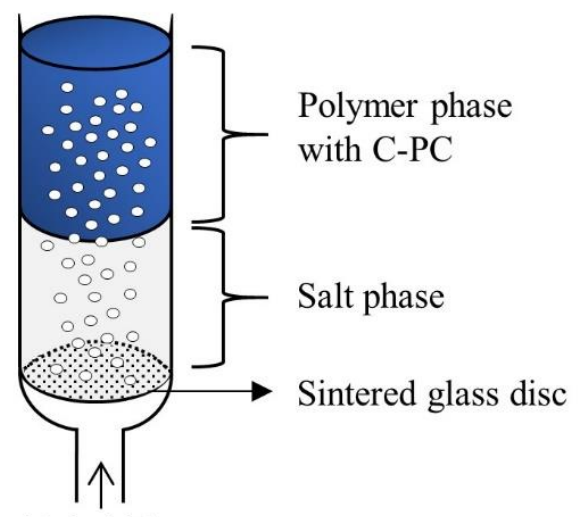

Air bubbles

Figure 1: Schematic diagram of the PEG/salt-based LBF for the purification of phycocyanin from Spirulina. The flotation effects created with the air bubbles assist in the upwards flow of phycocyanin from the bottom aqueous salt solution to the PEG-rich top phase.
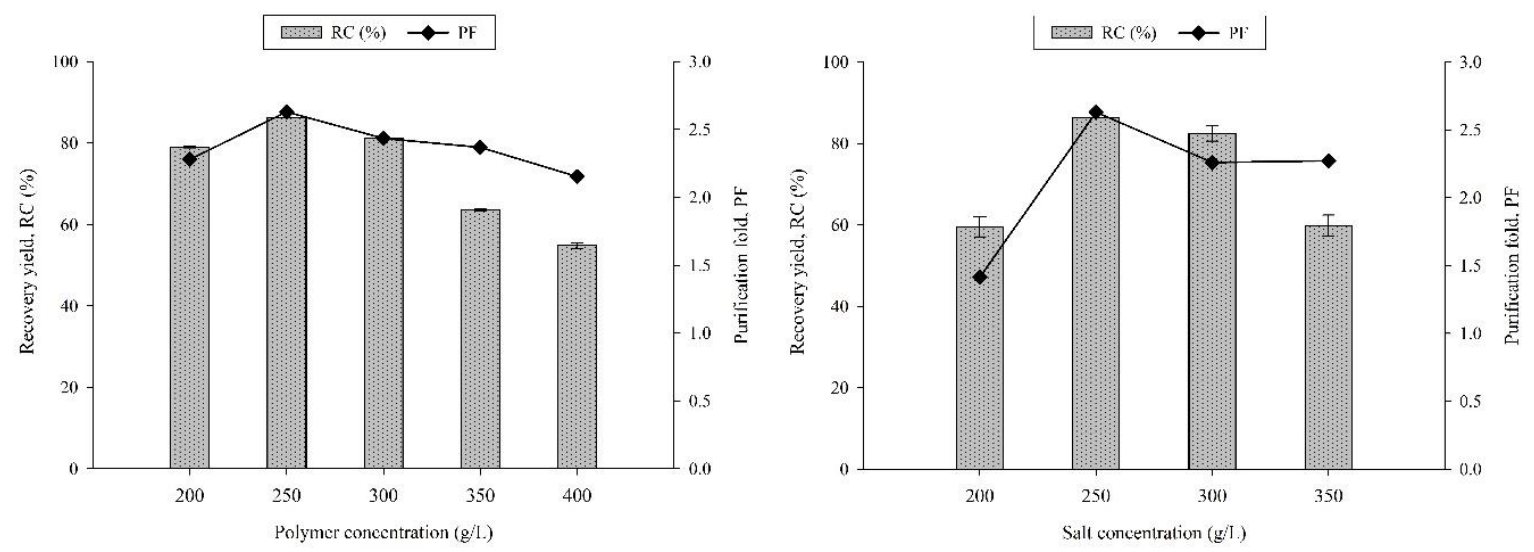
Figure 2: Effect of polymer and salt concentration $(\mathrm{g} / \mathrm{L})$ on the C-PC recovery yield and purification fold from S. platensis. (a) Variation in polymer concentration; (b) Variation in salt concentration.
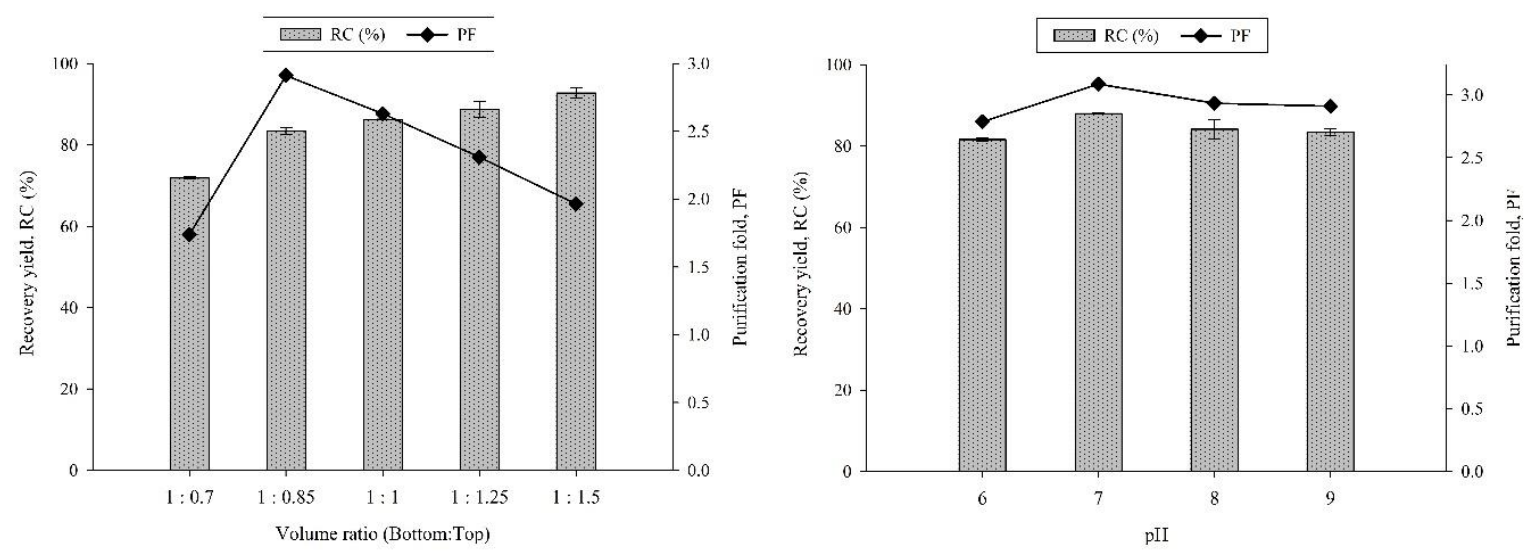

Figure 3: Effect of volume ratio and $\mathrm{pH}$ of the system on the C-PC recovery yield and purification fold from S. platensis. (a) Variation in volume ratio; (b) Variation in $\mathrm{pH}$ of the system. 


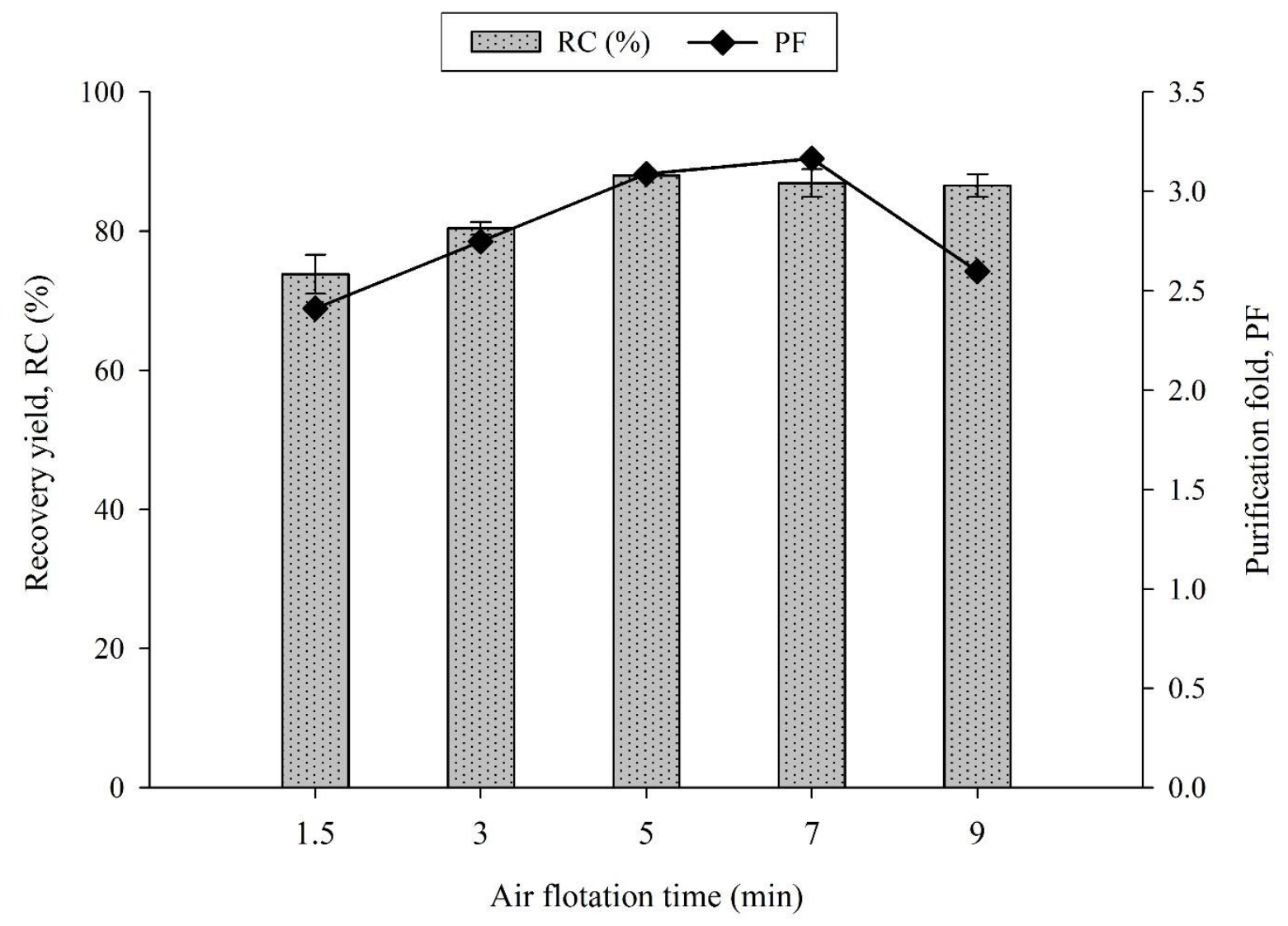

Figure 4: Effect of air flotation time (min) on the C-PC recovery yield and purification fold from S. platensis. 


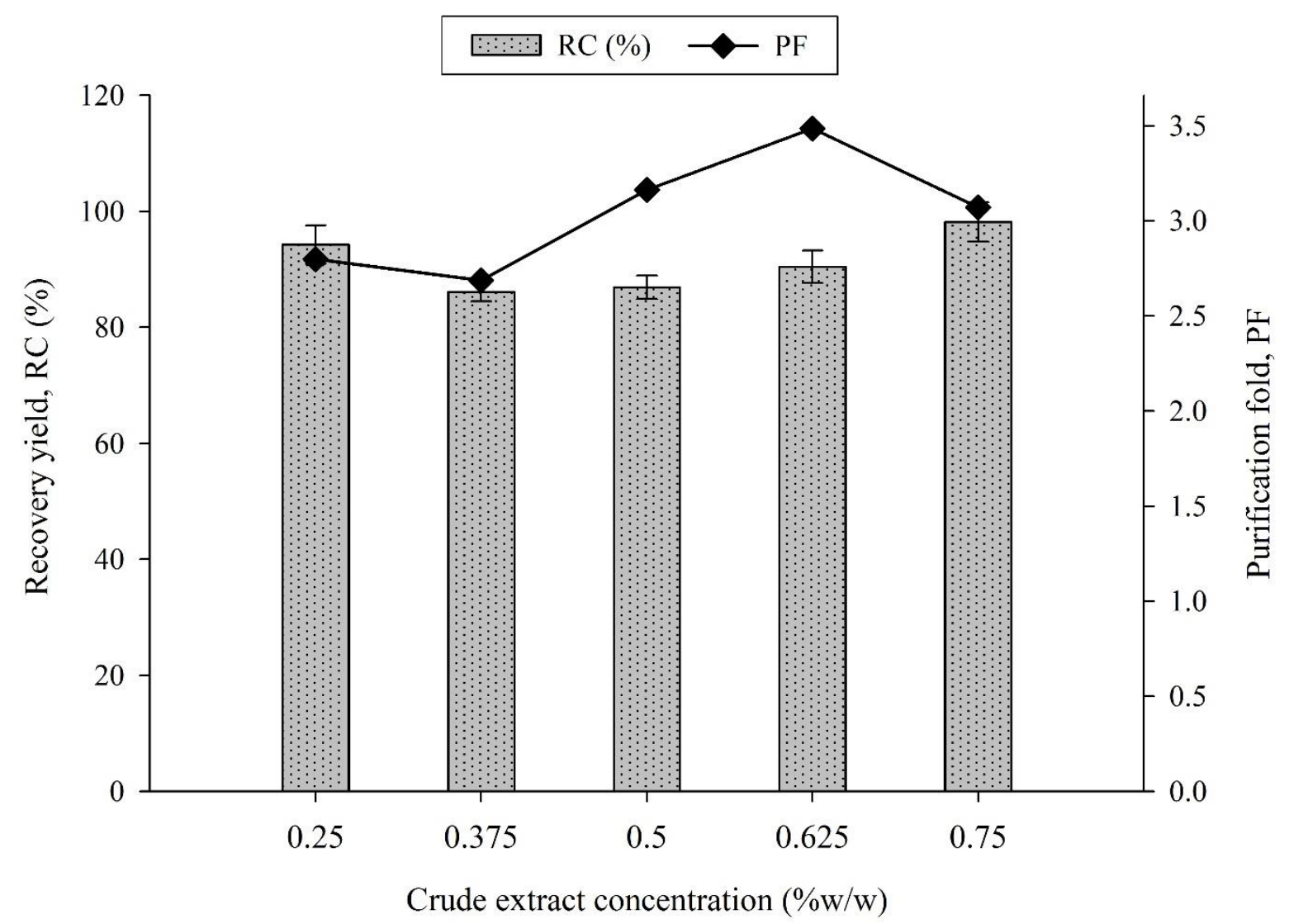

Figure 5: Effect of crude extract concentration $(\% \mathrm{w} / \mathrm{w})$ on the C-PC recovery yield and purification fold from S. platensis. 


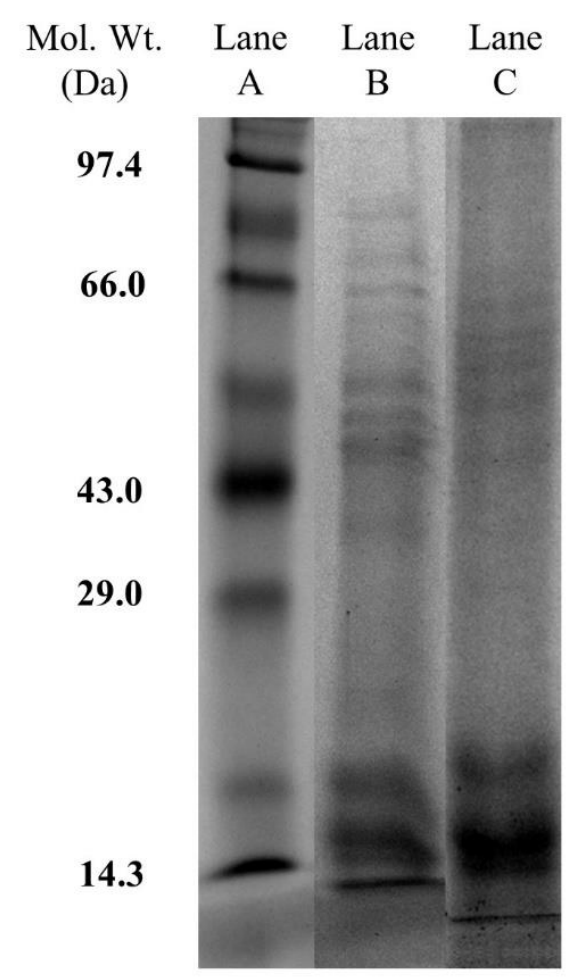

Figure 6: SDS-PAGE of C-phycocyanin: Lane A indicates the molecular marker; lane B indicates the crude extract of C-PC; and lane C shows the C-PC after LBF process. 
